\title{
VIGNETTE
}

\section{Coin Extractor}

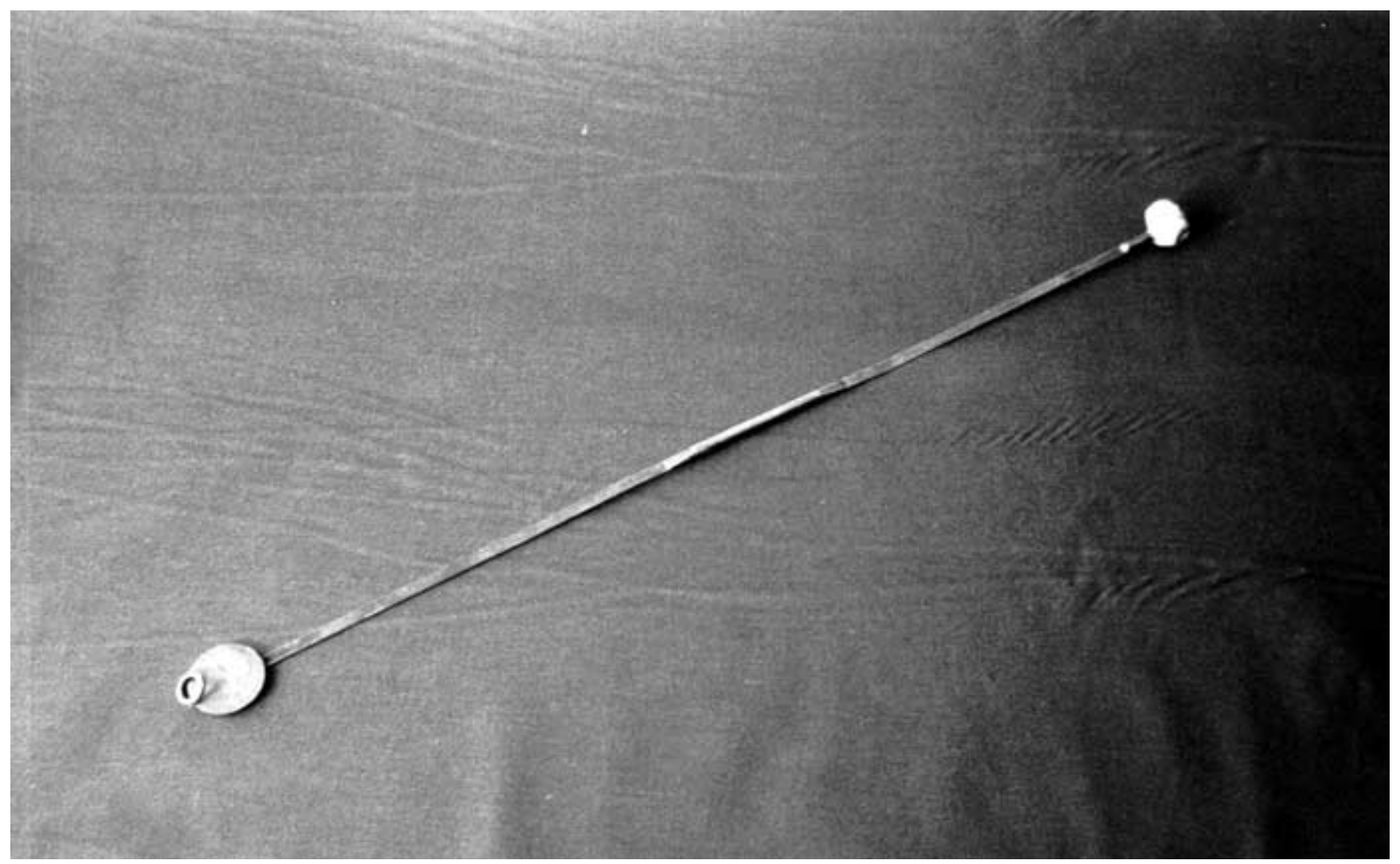

Throughout time soldiers have been prone to malingering in some cases as a means to get them out of the firing line. One practice was to swallow a half penny, which would then get stuck in the Oesophagus.
This coin extractor is $40 \mathrm{~cm}$ long and has been locally manufactured to enable the halfpenny to be hooked and withdrawn.

PH Starling Curator AMS Museum 